\title{
E-cigarettes and the marketing push that surprised everyone
}

\author{
Ongoing debate in Europe over regulation may favour the interests of the industry
}

\author{
Martin McKee professor of European public health
}

London School of Hygiene and Tropical Medicine

Many important conversations at the European Regional Committee of the World Health Organization take place in the corridors. This year, at its meeting in Izmir, Turkey, a common topic was the dramatic rise in the marketing of e-cigarettes now being seen in many countries. Where they are allowed, advertisements seem to be appearing everywhere. New outlets are also appearing, in some cases beside schools, as in Slovenia. Governments that had imposed restrictions have been coming under pressure to relax them from manufacturers and, in some cases, from groups portraying e-cigarettes as an effective means of harm reduction.

Many in Izmir wondered whether this intense activity was confined to their own country, but it was soon clear that this was something affecting all of Europe. But why now? The e-cigarette, a battery powered device designed to mimic smoking and to deliver a dose of nicotine without many nasty cancer producing substances in conventional cigarettes, has been around for a long time. The first patent was in 1963, and China has been exported e-cigarettes since 2005 . Nobody had seen the big marketing push coming. What has changed?

As we discussed the various experiences the answer emerged. When e-cigarettes first became available the big tobacco companies ignored them, as they thought they would never replace the real thing. After all, manufacturers had worked for many years to get the ingredients of their cigarettes just right. Not the tobacco, of course: it was all the other things they put in, such as ammonia, to ensure that the nicotine would be absorbed faster. This was so that children and teenagers starting smoking would be hooked by the nicotine kick before they were put off by the coughing and to reduce the risk of adults overcoming their addiction. Or menthol and other flavourings, again designed to appeal to youngsters. The products were perfectly designed to achieve what the manufacturers wanted: more young people smoking and fewer adults giving up.

But several things have changed. Firstly, countries introduced bans, of varying strength, on cigarette advertising. Of course, the companies managed to get round many of the bans, through positive portrayal of smoking in movies or on social media. Or by brand stretching: launching other products, such as clothing ranges, with the same name that could be advertised legally. Or by clever use of imaging - you don't need to write Marlboro on the distinctive red and white images for teenagers to know what they mean. But with every new generation the companies needed to reconnect their marketing with the act of smoking. E-cigarettes look like the real thing and offer the perfect opportunity.

Secondly, many countries banned smoking in public places. Smokers have used this as a stimulus to quit. After all, who wants to go out in cold or wet weather every time you want a nicotine fix? Once again, e-cigarettes came to the rescue, offering the possibility for people to get their fixes and remain addicted while staying warm and dry.

But the final factor was that smoking was becoming socially unacceptable in many countries. Many of those present in Izmir described how the tide had turned in their countries, with smoking regarded as an addiction and with those who smoked given sympathy and support. Certainly smokers were no longer looked up to. Tobacco control advocates can take much of the credit, pointing out that the Marlboro man didn't ride off into the sunset but died a lingering death from cancer. Even those celebrities who did smoke were embarrassed to be seen doing it in public. This change in attitude is what the tobacco companies feared most. So what they needed was for the people who are role models to young people to do something that may not exactly be smoking but that looks very much like it. There is even a helpful website showing who these celebrities are. ${ }^{1}$ Unsurprisingly, e-cigarette use has risen rapidly among US teenagers in the past year, many of whom are also smoking the real thing. ${ }^{23}$

But can't e-cigarettes help people to quit? This is the line that the tobacco companies are pushing in some countries, although they are careful not to make health claims where this would mean that their products would be regulated as medicines, as they are in Denmark, Lithuania, and Slovenia. In fact, the vast 
majority of people who quit smoking do so without help. A recent, widely quoted study showed that smoking e-cigarettes could help some people quit but that it was no more effective than other means of nicotine replacement. ${ }^{4}$

Many well respected public health professionals have advocated e-cigarettes as a form of harm reduction, as they are obviously much safer than smoking real cigarettes. But this may be missing the point. There are many other ways for people who cannot shake of their addiction to get their nicotine fix, none of which have the enormous downside of glamorising smoking again.

The debate is now moving to the European level and is intense in the European parliament, to the delight of the tobacco industry, as it threatens to delay the long awaited Tobacco Products Directive, justifying the vast lobbying resources the industry has deployed in Brussels. ${ }^{5}$ The parliament is divided between those party groupings supporting the European Commission's recommendation that e-cigarettes be regulated as a medicine and those who support their much less rigorous regulation as consumer products. However, the conversations in Izmir suggested a growing consensus among national governments in favour of going down the medicines route, as will happen in the United Kingdom, even while the groupings of MEPs that include the UK's Conservatives and Liberal Democrats favour the consumer products route in Brussels. Some governments have also taken advantage of wording in existing tobacco advertising bans that includes objects that look like cigarettes, as in Finland, Lithuania, and Slovenia. What is clear is that the more attention policy makers give to the aggressive marketing of e-cigarettes in their own countries, the more they conclude that the downsides far exceed any benefits.

Competing interests: None declared.

bmj.com News: E-cigarette use doubles among US middle and high school students (BMJ 2013;347:f5543, doi:10.1136/bmj.f5543);

E-cigarettes as good as patches in helping to reduce smoking, study concludes (BMJ 2013;347:f5505, doi:10.1136/bmj.f5505)

Observations: Big Tobacco lights up e-cigarettes (BMJ 2013;346:f3418, doi:10.1136/bmj.f3418)

Feature: Electronic cigarettes: medical device or consumer product? (BMJ 2012;345:e6417, doi:10.1136/bmj.e6417)

Head to Head: Should electronic cigarettes be as freely available as tobacco? (BMJ 2013;346:f3845, doi:10.1136/bmj.f3845; 2013;346:f3840, doi:10.1136/bmj.f3840)

Provenance and peer review: Commissioned; not peer reviewed.

Aviator. 5 uber-famous celebrities that vape. http://aviatorclub.com/5-uber-famouscelebrities-that-vape.

2 McCarthy M. E-cigarette use doubles among US middle and high school students. BMJ 2013;347:f5543.

3 Corey C, Wang B, Johnson SE, Apelberg B, Husten C, King BA, et al. Notes from the field: electronic cigarette use among middle and high school students-United States, 2011-2012. MMWR Morb Mortal Wkly Rep 2013;62:729-30.

4 Bullen C, Howe C, Laugesen M, McRobbie H, Parag V, Williman J, et al. Electronic cigarettes for smoking cessation: a randomised controlled trial. Lancet 9 Sep 2013. doi:10. 1016/S0140-6736(13)61842-5.

5 Doward J. Tobacco giant Philip Morris "spent millions in bid to delay EU legislation." Guardian 7 Sep 2013. www.theguardian.com/business/2013/sep/07/tobacco-philip-morrismillions-delay-eu-legislation.

Cite this as: BMJ 2013;347:f5780

๑ BMJ Publishing Group Ltd 2013 